Historic, archived document

Do not assume content reflects current scientific knowledge, policies, or practices. 


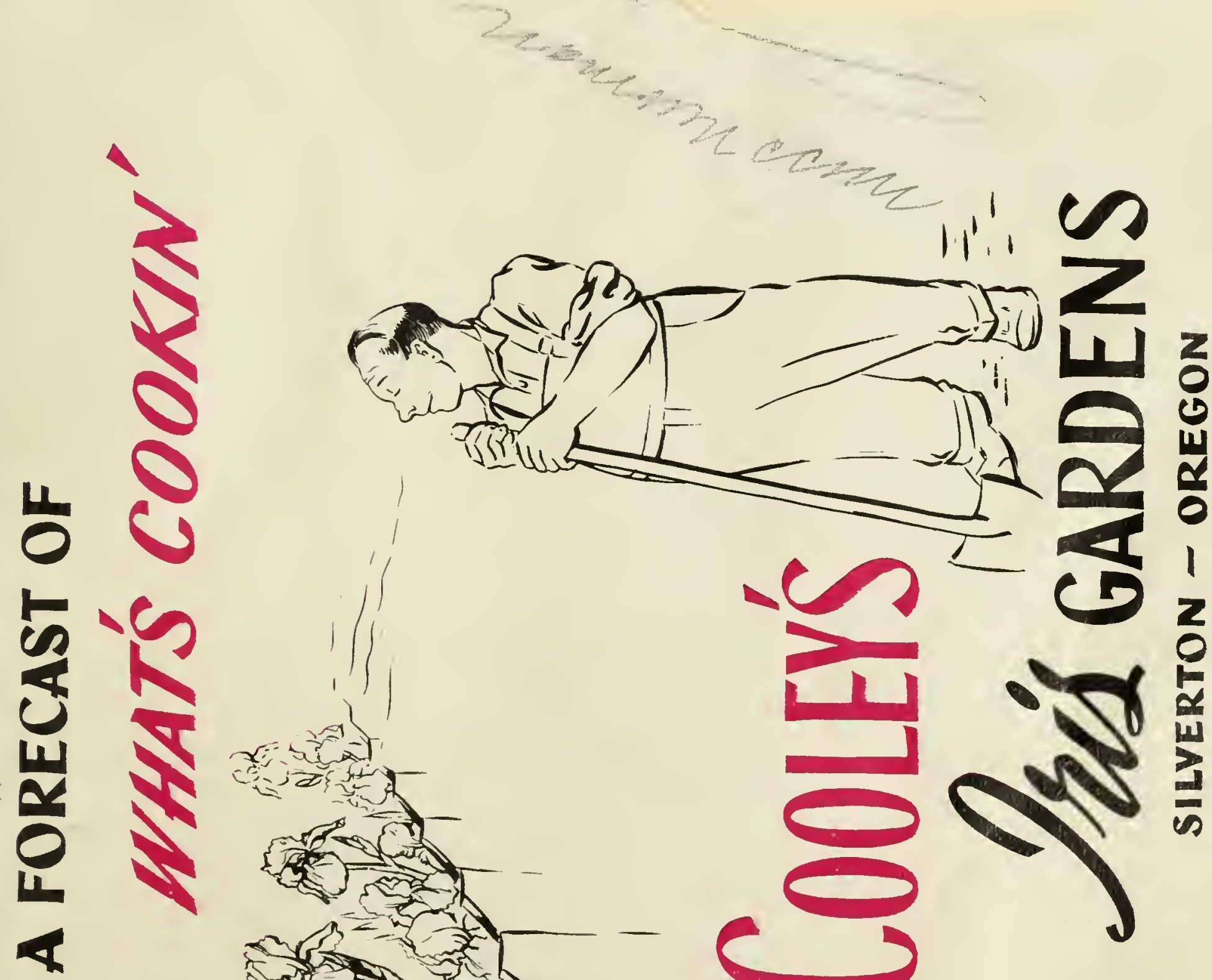



\section{COOLEY, GARDENS}

March 1, 1843.

\section{Of course, you are GARDENING this year!}
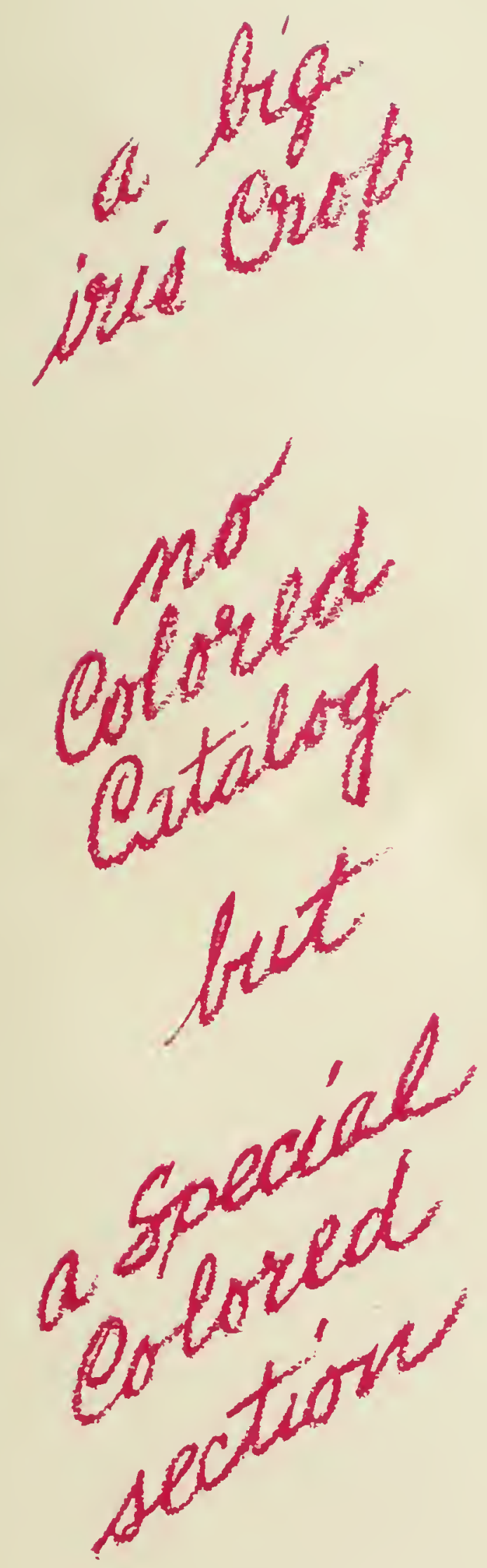

It's going to be America's Number 1 Hobby..... now that travel is out, most of the things we used to do for diversion and recreation are no longer possible. Yes, there are shortages on every hand, but

\section{WE HAVE A CROP OF SIX ACRES OF THE FINEST IRISES!}

And that brings us to the subject of "what's cookin'n.... We are having to make some changes, too. For the first time in over a decade our usual catalog in color will be missing. We know that you will understand that this heavy expenditure must be foregone this year. But we have a plan which keeps unbroken our tradition of presenting NEW IRIS IN COLOR every season....here it is:

A complete catalog section, $12 \times 8$ inches, in NATURAL COLOR, showing the 1843 new introductions along with complete descriptions, will be made up during the current blooming season. It will be exactly the same page size as the $184 I$ and 1842 catalogs.

This 1843 colored supplement is FREE, but you must reserve your copy now if jou want it. Positively no more than the number reserved in advance will be printed because of the cost involved. You can do this today as explained on the next page, either by mailing the coupon promptly back to us, or by placing an order for June delivery as selected from the succeeding page.

These SIX LARGE COLOR PLATES will probably be the last full-color iris pictures we shall be able to bring you until after the war. Order your copy now, and then preserve it along with your last complete catalog until such time as we can again bring jou America's finest iris catalog.

Whether you ask for the colored section only at this time, or accompany your request with an advance iris order, you will be definitely assured of a copy. But because of labor shortages and severe marketing and shipping problems, we offer the suggestion that an iris order placed on file NOW will be the first to reach the customer..... first received, first shipped, first planted, best results!

Read the contents of this message thoroughly, then take the necessary few seconds to fill out the coupon and mail it back to us today. 


\section{the New things we HAVE IN STORE FOR YOUR 1943 GARDEN}

\section{Birst, there are the New Jutroductions.}

Every dyed-in-the-wool flower grower wants to know about them, even though they may not find their way into your own particular garden until some future date. Here they are-

\section{From DR. R. E. KLEINSORGE}

OREGON TRAIL. A big heavy textured flower in smoothly blended shades of tawney.salmon. There is a rich gold beard and odd soft brown areas surmounting the falls. Dr. Kleinsorge nicknamed this iris "Brown Shoulders" but the name finally chosen is in honor of the 100th anniversary of the founding of the state of Oregon. This distinct blend of rich colors, much deeper and more vivid than such things as Sandalwood, Far West, or Fiesta, ranks along with Old Parchment, Tobacco Road and Aztec Copper for sheer individuality. Medium in height, three feet or slightly over, with heavy stems and large flowers; very late.

Each $\$ 15.00$

RANGER. Dark but very brilliant almost true crimson red. A decided self, with long cone-shaped closed standards. Now that many new near red irises are coming to us each year, we must exercise caution before introducing another. We grew the best new reds obtainable for comparison, with the result that we were convinced beyond doubt that RANGER is in a class by itself. Nearest to it is Red Valor. One of the last to bloom, a sure producer of flowers and lots of them, with straight stems and fine branching. Very large, 36 inches tall.

Each $\$ 10.00$

PEACH GLOW. A seedling of Daybreak and another truly beautiful almost true peach-pink iris. While the individual flowers are large and perfectly proportioned, it is as a garden clump that this lovely creation is startlingly effective. The tall wiry stems bear a great number of flowers which last from early mid-season to late. As colorful and luscious as a bowl of Georgia peaches.

Each $\$ 10.00$

ILLUSION. An Ormohr seedling, altogether different from either the parent or any others in this series, but with the peculiar elusive different air about it that marks these Wm. Mohr hybrids. ILLUSION is delicate lilac pink in color, with tawny brown overlay on the haft and a brown tipped beard having a slight crest at the end. The very last iris to flower in our garden, it is a mass of huge blooms of ethereal lilac pink color, but slightly smaller in size than Ormohr. Well branched, about 30 inches tall, with some stems slightly taller.

Limited stock, $\$ 10.00$ each.

MEXICO. Gay and brilliant, a blended bi-color of buff golden standards and broad plush-like falls of glowing red brown. Now there are many irises in this color combination, but this one is not the ordinary variegata type that you might expect. In the first place, it is a perfectly gigantic flower, with the falls slightly waved at the edges. And then there is a coppery orange suffusion about it that makes it appear more as a blend than a definite bicolor. This is another of the very latest varieties, extending the iris season after most others have passed by.

Each $\$ 10.00$

\section{From EDGAR BECK, Chattanooga, Tenn.}

MISS ANN. In 1941 we heard about the splendid seedlings raised by Mr. Beck, a Chattanooga amateur. Two of the finest ones were sent to us for trial and we selected this one for introduction. Most difficult to describe, it is a blend of pearly pink tones, a magnificent iris with very broad falls and huge standards, as nearly perfect in shape and style as one might wish for. It contains the fleeting tints found in an opal, but the blossoms are of thick substance and endured the pouring rain and heavy wind we experienced last season as though they were fashioned out of enamel. A beautiful and thoroughly fine iris.

Each $\$ 10.00$

\section{and then there are these BRAND NEW VARIETIES,}

selected from the cream of fine irises recently offered by other introducers, and which we list for the first time-

Berkeley Gold, a gorgeous rich yellow; Capitola, a bright red violet hybrid, something like Wm. Mohr; Melitza, pale flesh pink; Edward Lapham, a brilliant red, said to surpass Red Gleam; Lady Naomi, something different in 
This is the first time that we have published our complete price list for the coming season so early in the year. We are doing so now to lessen the rush that always comes in June and early July . . . and by ordering now, you definitely make sure of two important things:

1. You will get your order filled completely, exactly as you want it. No second choices, no substitutions.

2. Delivery will be made right off the bat, in June, so that your plants will have all summer to grow for you.

Jrises ARE ONE LUXURY YOU CAN STILL HAVE IN YOUR GARDEN

A glance at this list will convince you that prices of EVERYTHING have not soared upward! You can buy the novelties and rare varieties for much less than you could a year ago ... check these prices against last year's catalog. Even many of the lower priced sorts have been further reduced.

Your special attention is invited to the new collection groups on the back of this folder.

\section{A}

F

Alastor, very deep pink, hazel brown haft.

Aline, one of the bluest of blues.

Allumeuse, mahogany falls, blue standards.

Amitola, dusty pink and yellow, huge.

Amigo, blue standards, deep indigo falls

Angelus, very late pink blend.

Anitra, big domed light blue.

Apricot, free flowering apricot self.

Arctic, sensational creamy white and gold.

At Dawning, blend of pearly pink and rose.

Aubanel, a shrimp-pink blend, very lovely.

A vondale, unusual fuchsia red, late.

Aztec Copper, huge blend of violet and copper.

Balmung, big yellow plicata, extra fine. Bataan. 1942 introduction of coppery plum Bermuda Sand, a glorified Jean Cayeux. Beverly, a new prolific flowering pink blend. Birchbark, pure white, greenish glow in center Berkeley Gold, very new deep yellow.

Black Valor, deep blue-black, rather short. Blue Danube la flowered clean blue. Blue Diamond glistening bright sky blue. Blue Diamond, glistening bright sky blue. . Blue Spire, giant light blue from California. Bonanza, exceedingly deep yellow plicata. Bo Peep, sprightly creamy pink, very tall. Brown Boy, an improved Radiant. .. Brown Thrasher, new coppery brown self. Brunhilde, uniform violet blue, blue beard Buckskin, tall large flowered tan.

\section{$\mathrm{c}$}

Calcutta, odd cocoa-brown self

California Gold, most popular yellow.

California Peach, new blend of peach pink

Capitola, bright reddish violet hybrid. .

Caroline Burr, beautiful greenish cream.

Casque d'Or, old gold standards, blackish falls.

Carved Ivory, solid ivory self, fine form. ...

Cheerio, most popular near red self.

Cheerio, most popular near red self........

Charm, late strawberry red, medium height.

Charm, late strawberry red, medium he
China Maid, exceptional pink blend...

Christabel, one of the very best reds.

City of Lincoln, the very finest variegata

Claret Velvet, deep ruby of plush-like quality

Copper Lustre, copper blend, absolutely distinct.

Corinthe, deep purple, white beard, late.

Coronet unusual biege and apricot...

Cyrus the Great, blackish purple, very large.

$$
\text { D }
$$

Damarine, rich deep red, extra fine color. Darbreak, truly an outstanding new pink. Deep Velvet, the very finest deep purple. . Derrill Hart, extra large bronzy rose-crimson. . Derrill Hart, extra large bronzy rose-crimson. Destiny, rich blackish purple, extra quality. Directeur Pinelle, maroon purple, bronze cast.

E. B. Williamson, glowing copper-red blend. Elizabeth Ann, 4-foot pink, extra late. Edward Lapham, said to be the reddest iris Elmohr, new violet-toned Wm. Mohr seedling. . . Elsa Sass, delightful lemon-yellow self Eros, tall salmon pink, very popular. Ethel Peckham, well known red toned self Ethiop Queen, almost solid black. Evelyn Pullar, winter blooming in mild climates. Exclusive, light powder blue, a fine iris. . ...

Fair Elaine, two-toned yellow, prolific grower

Far West, rare blend of salmon and pale but

Fiesta, tints of orange and apricot, tall...........

Flora Campbell, striking russet red, very rich...

Fortune, a new red-old-gold of great size.

Frank Ádams, bicolor of rosy tan, soft red.

Gallant Leader, a giant in deep copper red. Garden Magic, unsurpassed ruby red, late

Glen Ellyn, old ivory washed with brown.

Gloriole, sparkling frosty blue.

Glowport, deep wine red, fall bloomer

Golden Fleece, bright canary yellow and gold...

Golden Fleece, bright canary yellow and gold..

Golden Hind, deepest and richest pure yellow

Golden Madonna, big ruffled creamy yellow.

Golden Majesty, solid yellow, runner-up for Dykes 1.50

Golden Spike, new solid yellow, extra fine.

Golden Treasure, brilliant cream-orange.

Good Cheer, orange yellow and striped brown.

Grand Canyon, blend of coppery plum and b

Gudrun, huge cream white, golden center

Gypsy Barron, a brand new and different plicata.

$\mathrm{H}$

Happy Days, largest of all yellows, early

Icy Blue, just a shade bluer than white, fine.

Indian Hills, lively shade of brilliant violet.

Idanha, new bi-color of apricot and lilac pin

Imperial Blush, lilac pink self, tall and fine.

Incognito, swarthy deep violet black, tall.

Iris City, amethyst purple, very tall.

$$
\text { J }
$$

Jasmania, big banana yellow

Jean Cayeux, pale coffee tan,

Joycette, very late maroon red.................

Junaluska, $a$ wonderful iris, bright copper red.

\section{$\mathrm{K}$}

Kalinga, solid cream, good grower, free bloomer

Khorasan, blend of henna and old gold. .

\section{L}

Late Sun, surprisingly fine golden yellow . . Lancaster, copper pink, very broad falls. Lady Naomi, in our opinion the best plicata. . Lighthouse, bright rose and yellow blend. .

Lodestar, a late variegata, small but bright.

Louvois, velvety brown in two shades, gorgeous.

M

Marco Polo, excellent red, similar to Cheerio.

Marquita, ivory yellow, falls veined maroon.

Mary Geddes, salmon-orange effect, very good.

Matula, brilliant rose, orange and buff.

Matterhorn, purest white, large and tall

May Day, large apricot-salmon.

Mary E. Nicholls, ivory white and gold.

Marinella, new French yellow-crimson

Meldoric, a well known velvety purple.

Melitza, pale flesh colored, real novelty

Ming Yellow, marvelous yellow without a faut

Miss California, very tall lilac pink.

Missouri Night

Missouri, fom

Mme. Louis Aureau.

Modiste,

Mohrson.

Monadnock,

Morocco Rose.

Mrs. Willard Jacques

Mi. Washington,

Mulberry Rose,

Narain,

Noontide,

Noweto

Nylon,

Old Parchment,

O

Ormaco

Ormohr,

Orlotf,

Oyez,

Patricia

Pailaisse

Piute,

Pink Ruffles,

Prince of Orange.

Radiant,

Rebellion,

Rhapsody,

Red Valor

Red Radiance

Rosario,

Roseland,

Rosy Wings,

Royal Coach

Ruth Pollock,

Sable, a magnificent blue-black

Salar, creamy flesh, overlaid salmo

Sandalwood, fawn-brown blend, salm

Sandia.

Satsuma

Seadeep,

Setting Sun

Shah Jehan

Shawano,

Siegtried.

Sierra Snow, ex

Sioux City

Smolder

Snoqualmie,

Southern Pacific.

Snowking,

Spokan,

Spring Idyl,

Spun Gold,

Stained Glass, copper-red self, glowing
Stella Polaris, tall and large cream white.

Storm King guite likely cream white.

The Black Douglas

The Red Douglas.

Three Sisters

The Darb,

Titian Lady,

Tiffany, most

Tobacco Road.

Token, standar

Treasure Island,

Velvet King,

Violet Symphony.

Wabash,

Wm. Moh

Waverly,

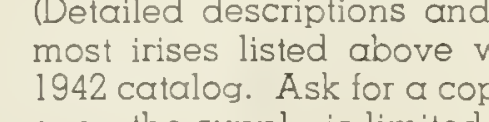

.60

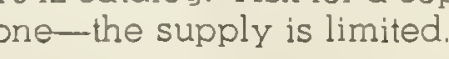






\section{Please Note!}

$\star$ If your order is placed before APRIL 1st, you will receive the special color section described in this folder. All orders will be filed for shipment immediately after the blooming season.
ORDER BLANK

Cooley's Gardens

SILVERTON, OREGON

Date

Ship to

Street or R.F.D.

City.

State

Date wanted.

Amount enclosed.

SUBSTITUTIONS will not be made unless you request. If supply of a variety you have ordered is exhausted, may we send you another, of equal or greater value? Please answer

yes or no.

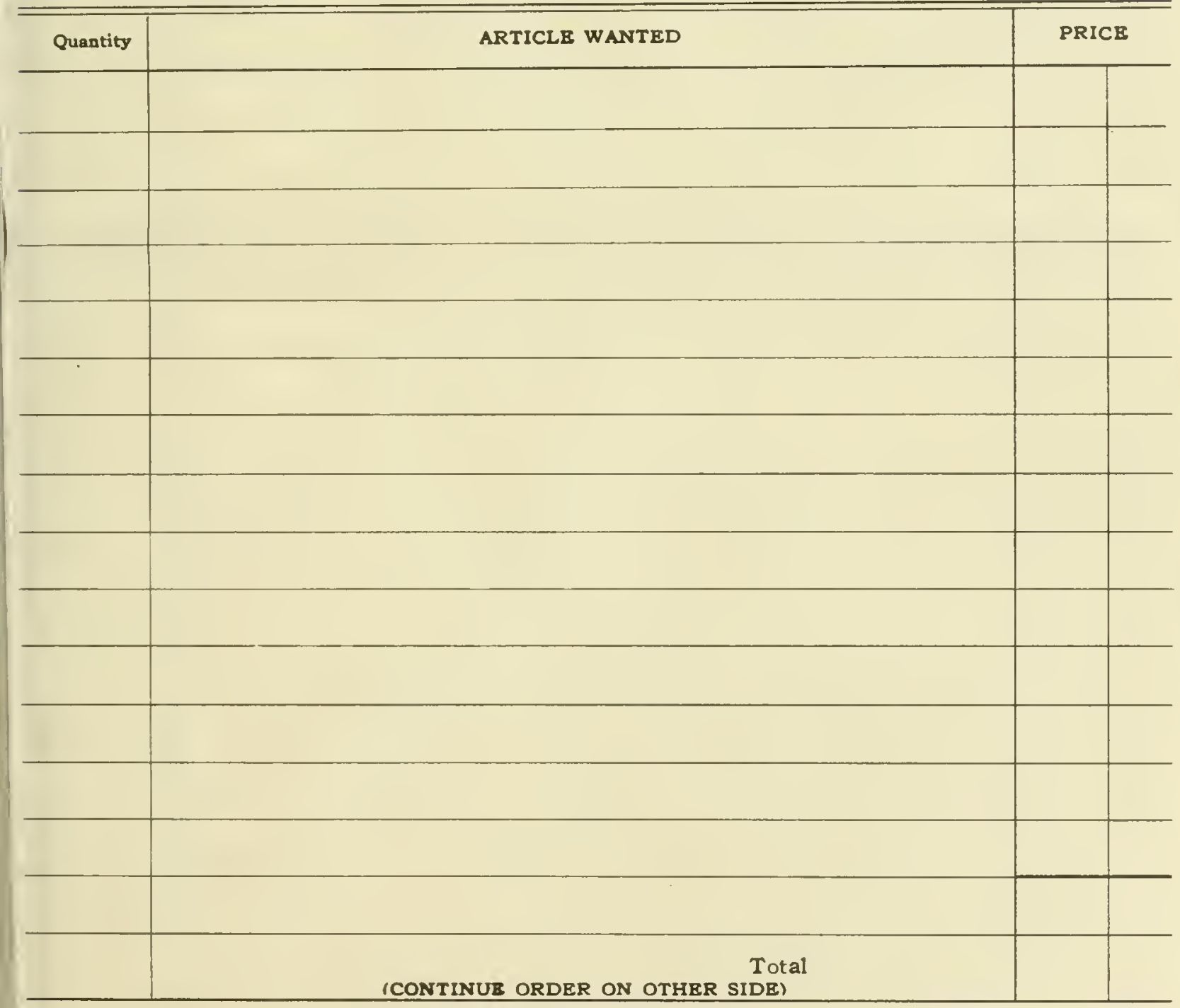

GROUP PRICES FOR PLANTS OF ONE VARIETY

One Plant Three Plants One Plant Three Plants

$\begin{array}{rrrr}\$ .25 & \$ .60 & \$ .50 & \$ 1.25 \\ .30 & .75 & .60 & 1.50 \\ .35 & .90 & .75 & 2.00 \\ .40 & 1.00 & 1.00 & 2.50\end{array}$

If your order is for a collection, and you wish to take advantage of the

2.00 FREE IRIS for assuming

2.50 express charges, check here 


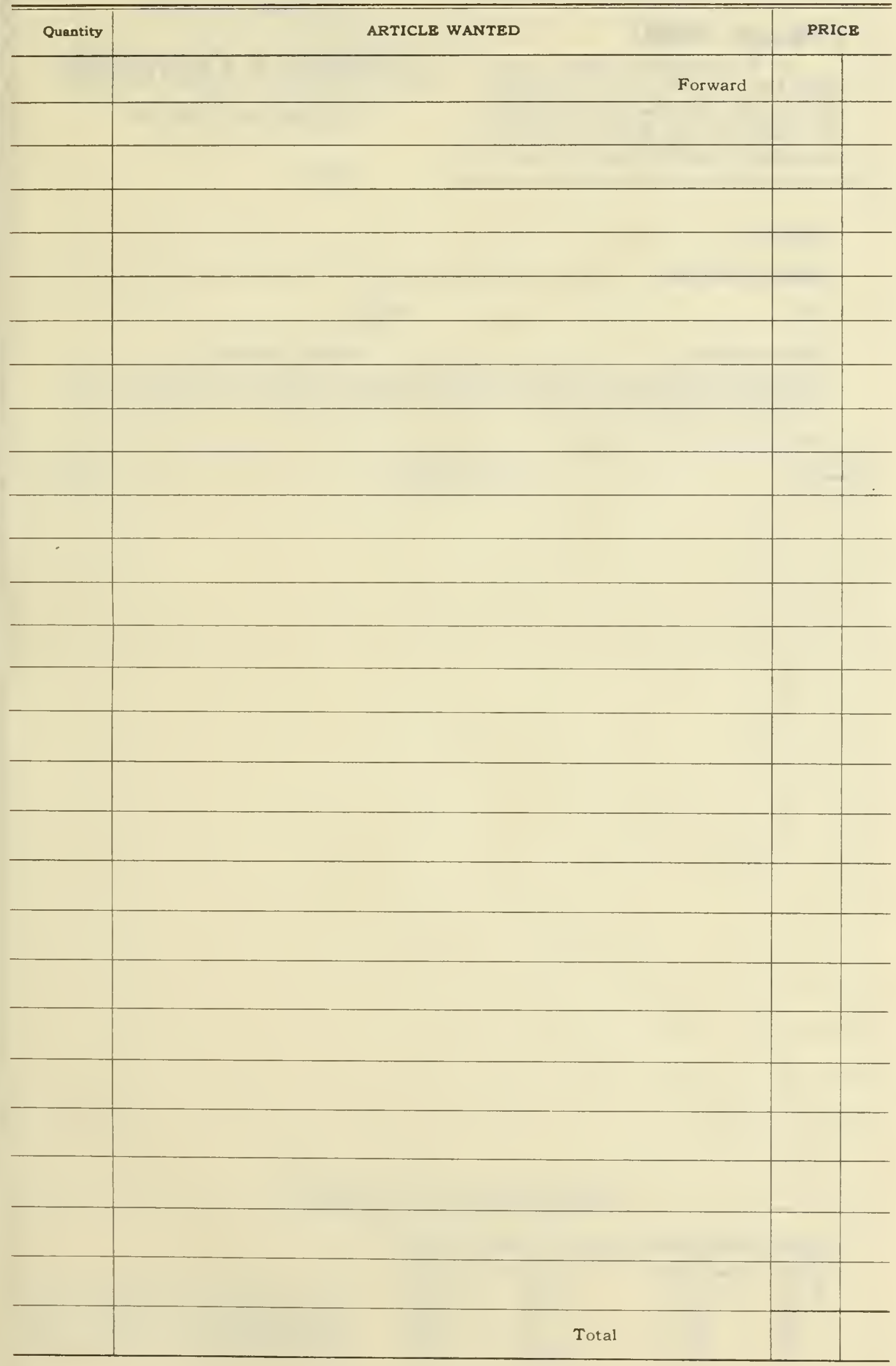



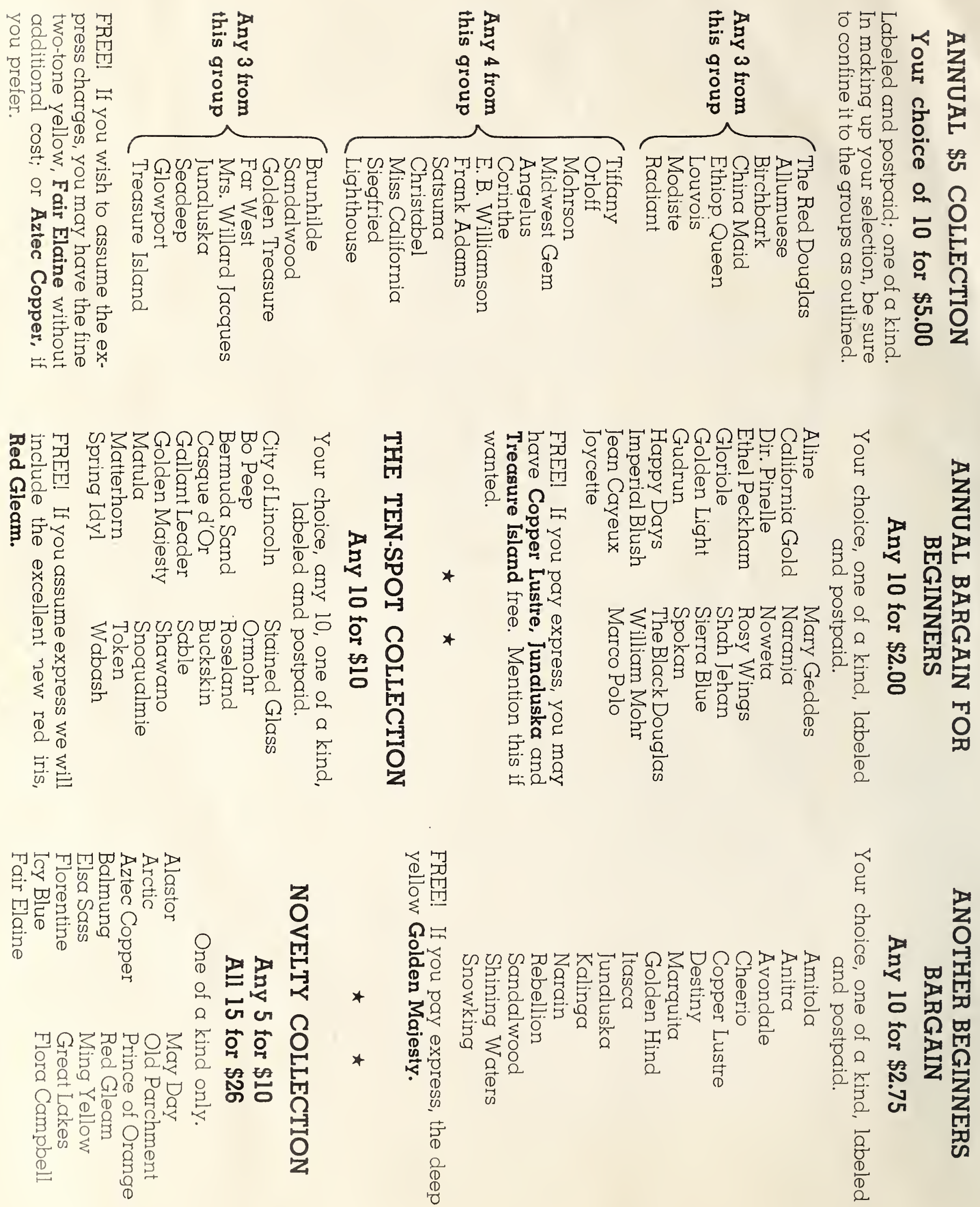